\title{
Prêmio Universidade Corporativa Banrisul
}

\section{Marta Silva Neves}

Analista da Universidade Corporativa Banrisul. Pedagoga. Mestre em Ensino na Saúde. Especialização em Gestão Social. Formação em Dinâmica dos Grupos.

E-mail: marta_neves@banrisul.com.br

\section{DOI: http://dx.doi.org/10.21674/2448-0479.44.539-541}

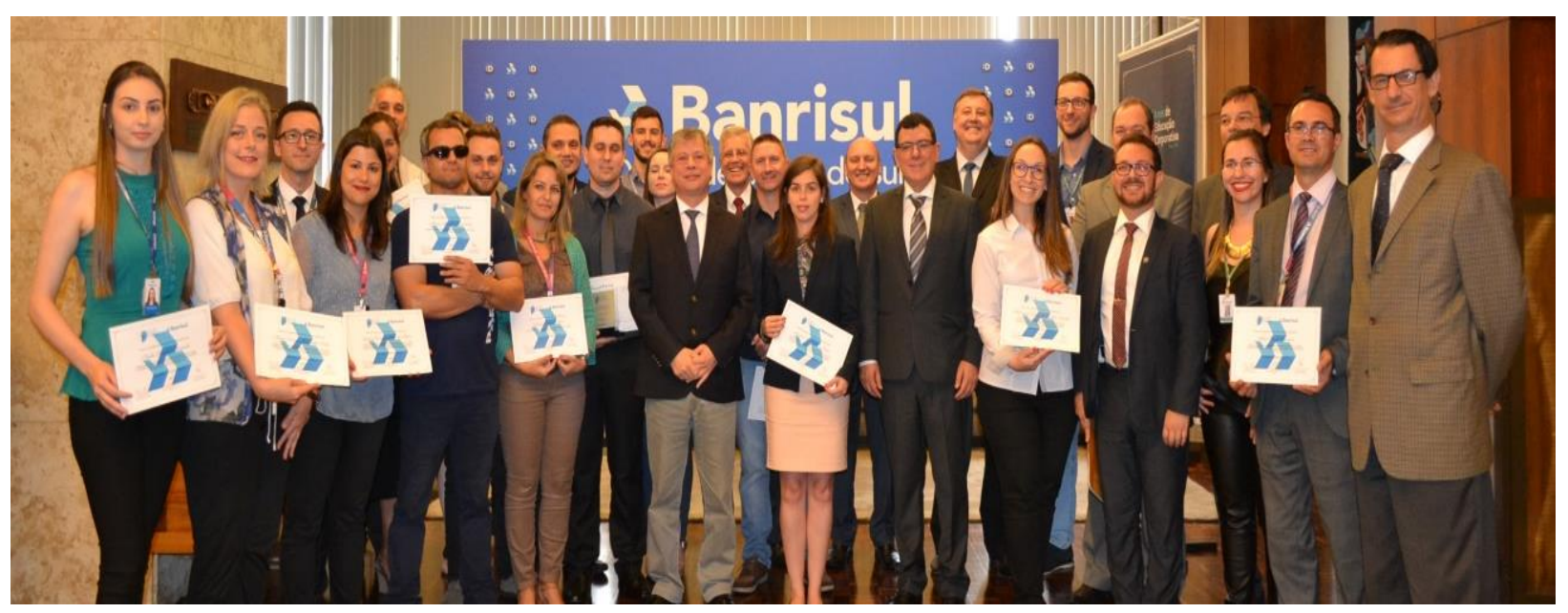

Esta edição especial da Revista Eletrônica Científica da UERGS compartilha artigos elaborados por colaboradores do Banrisul com temas referentes à gestão bancária. As produções são oriundas de cursos de graduação e pós-graduação, que participaram do Prêmio Universidade Corporativa Banrisul, que compôs as estratégias de celebração dos 50 Anos de Educação Corporativa dessa instituição financeira. 0 Prêmio voltado ao reconhecimento de projetos de pesquisa desenvolvidos, em formato de artigos, incentiva o espírito de inovação, a busca de conhecimento e a reflexão a respeito das ciências empresariais e suas tendências.

O Banrisul cresceu e ampliou significativamente ao longo do tempo seu quadro funcional, iniciando suas atividades em 1928 com apenas 30 empregados e uma organização interna distribuída em duas carteiras: uma carteira econômica e uma Hipotecária, já em 1958 o banco contava com 1.635 profissionais. A instrução e treinamento desses profissionais fundamentava-se no próprio ambiente de trabalho, em que os indivíduos, por meio das relações e interações, buscavam informações no meio, vivenciavam, influenciavam e modificavam-se, gerando as formas de conhecer, de aprender, de pensar, de constituir novas tecnologias e a própria instituição, o que é enfatizado como ecologia cognitiva, por Pierre Lévy (1998).

Em 1966, formaliza-se o processo de educação corporativa, sendo criado um setor voltado a formação dos profissionais, alinhado a operação dos negócios e à estratégia organizacional, passando a documentar e fomentar a criação de marcos importantes e muitas pessoas construíram a trajetória de realizações e conquistas que fizeram do Banrisul e atualmente, de sua Universidade Corporativa, referência no mercado de educação corporativa. 
Nesse sentido, amplia-se a possibilidade de colaboradores oferecerem conhecimento, por meio de um contexto que busca favorecer e incentivar o desenvolvimento das pessoas, das equipes e da organização, constituindo a inteligência coletiva, como é ressaltado por Lévy (2003). Essa compreensão instiga a organização a perseguir cada vez mais a produção do conhecimento, bem como seu compartilhar e aplicabilidade enquanto processo de construção dos indivíduos e da organização. Associa-se assim, a criação de espaços de ação onde se exercitem as habilidades e capacidades para reflexão do fazer e do que se deseja viver, como enfatiza Maturana (2000)

A Universidade Corporativa Banrisul, sob a condução do gestor Márcio Kaiser, desenvolveu várias iniciativas alinhadas a essa trajetória de 50 anos, no intuito de celebrar, valorizar e refletir a respeito da gestão da educação no Banrisul, com base nos pilares econômico, social e de desenvolvimento, acompanhando, sempre, as tendências do mercado. Entre as iniciativas está o Prêmio Universidade Corporativa, que recebeu diversos trabalhos acadêmicos. Para a avaliação dessas produções contou-se com a comissão julgadora externa, composta por professores e especialistas da UERGS, a fins aos temas avaliados. Entre os critérios avaliados estão: impacto positivo para a eficiência da gestão; Concordância com as temáticas do concurso; profundidade do conteúdo, considerando embasamento, análise de variáveis e foco; correção e coerência da linguagem; clareza e consistência dos conceitos e da abordagem; coerência das reflexões e conclusões; correto uso e atualidade das citações e autores(as) referenciados(as); adequação às normas da ABNT.

A possibilidade de publicação de artigos junto à Revista Eletrônica Científica da UERGS, considerou as produções que obtiveram pontuação entre 8 a 10. Os artigos destacados pela comissão avaliadora e que não haviam sido submetidos anteriormente a outras publicações, totalizam seis publicações que compõe esta edição especial, perpassando pelos temas economia, finanças, estratégia, marketing e gestão de pessoas, conforme segue:

$\checkmark \quad$ Políticas econômicas anticíclicas e seus efeitos regionais e setoriais utilizando um modelo de equilíbrio geral computável inter-regional

Nunes apresenta discussão a respeito da reformulação dos sistemas tributários medindo, por meio de simulações, os impactos econômicos de políticas tributárias anticíclicas e distinguindo resultados setoriais e regionais para a economia brasileira. A partir de um modelo de Equilíbrio Geral Computável (EGC), analisa os impactos sobre as variáveis PIB, consumo das famílias, poupança, investimento, gastos do governo, emprego agregado, salário real médio, índice de preços ao consumidor e produção setorial.

$\checkmark \quad$ Economias de aglomeração no brasil: evidências a partir de equações de rendimentos

Carraro analisa as economias de aglomeração no Brasil, a partir de equações de rendimentos. Por meio da Análise Exploratória de Dados Espaciais (AEDE), verifica a existência de associações espaciais salariais, tais como: regiões homogêneas (clusters) e observações atípicas (outliers). Utiliza equações salariais, com formulação baseada em um modelo desenvolvido por Fingleton, cuja principal hipótese aponta para uma relação positiva entre os diferenciais de salários e a densidade de emprego. 
$\checkmark \quad$ Definição de meta comercial para crédito e projeção de passivos com modelo ARIMA

Bandeira analisa o processo de definição de metas comerciais em instituições financeiras, resgatando o passado recente através da análise de séries temporais, valendo-se do modelo paramétrico ARIMA como ferramenta de apoio à tomada de decisão.

$\checkmark \quad$ Estudo de caso: o perfil do consumidor superendividado no projeto de apoio às famílias superendividadas do Prasjur e a educação financeira

Silva estuda o perfil de consumidor superendividado gaúcho, por meio de um estudo de caso sobre o superendividamento no âmbito do Projeto de Apoio às Famílias Superendividadas do Programa de Práticas Sociojurídicas da Unisinos (PRASJUR). Na análise faz correlações com os dados do Projeto Piloto de Tratamento das Situações de Superendividamento do Consumidor de 2007, além de outras experiências do direito comparado e educação financeira.

$\checkmark \quad$ Dados dos clientes: uma troca de valor entre empresa e cliente no setor bancário

Zinn traz a discussão a respeito da percepção do consumidor gaúcho em relação à coleta dos seus dados pelas instituições financeiras e as expectativas na troca de valor empresa-cliente pelos diferentes tipos de dados. A análise é desenvolvida a partir do estudo relativo ao Marketing de Relacionamento, ao Marketing com Bancos de Dados e os dados dos consumidores.

$\checkmark \quad$ O endomarketing como elemento motivador estudo de caso do Banrisul

Gil apresenta pesquisa a relevância do endomarketing nas organizações, analisando a percepção dos funcionários sobre o endomarketing realizado pelo Banrisul. O estudo tem como referência endomarketing, comunicação organizacional e gestão de pessoas.

No ano em que celebra 90 anos do Banrisul, exercitar essa partilha de saberes de profissionais tornase um dos marcos de cultura organizacional. Sinaliza assim, a perspectiva cada vez mais ampla de Universidade Corporativa, enquanto guarda-chuva estratégico para o desenvolvimento e a educação de seus colaboradores à diversidade de atores - clientes, fornecedores, membros da comunidade, otimizando estratégias organizacionais que contribuam para o contexto social, político e econômico em que se está inserido.

Boa leitura, reflexões e um trilhar cada vez mais direcionado aos processos de criação, compartiIhamento, estruturação, disseminação e utilização dos conhecimentos em rede!!!

\section{REFERÊNCIAS}

LÉVY, P. A inteligência coletiva: por uma antropologia do ciberespaço. 4.ed. São Paulo: Loyola, 2003. Tecnologias da Inteligência. São Paulo: Editora 34, 1993.

MATURANA, H.; REZEPKA, S. N. Formação humana e capacitação. 4. ed.São Paulo: Vozes, 2000. 